EDUR • Educação em Revista. 2020; 36:e231100

DOI: http://dx.doi.org/10.1590/0102-4698231100

() (1) $\mathrm{https://creativecommons.org/licenses/by/4.0/}$

Privatização da e na educação infantil

\title{
A EDUCAÇÃO INFANTIL SOB A LÓGICA DO EMPREENDEDORISMO E DOS “NEGÓCIOS DE IMPACTO SOCIAL"
}

BIANCA CORREA ${ }^{1}$

ORCID: https://orcid.org/0000-0003-1906-8729

\begin{abstract}
RESUMO: A educação infantil universal é conquista recente no Brasil, alcançada em 1988 com a nova Constituição Federal. O PNE de 2014 definiu como meta a matrícula de ao menos 50\% das crianças de até 3 anos em creches, reforçando a obrigatoriedade entre as de 4 e 5 anos. Todavia, segundo o INEP, em 2018, o atendimento era de $91,7 \%$ no caso da pré-escola e de 32,7\% no caso das creches. É nesse cenário que o mercado tem encontrado mais um nicho para a oferta de "novos produtos". Neste artigo, analisamos o material intitulado Empreendedorismo e negócios de impacto social para a Primeira Infância, cujo objetivo é "apoiar empreendedores interessados em desenvolver negócios de impacto para a Primeira Infância." A análise do documento indica como a pobreza nos anos iniciais da infância vem se transformando, de modo cada vez mais evidente, em mercadoria, ainda que sob o pretexto de uma nova forma de filantropia.
\end{abstract}

Palavras-chave: Educação Infantil, Empreendedorismo, Negócio de Impacto Social.

\section{EARLY CHILDHOOD EDUCATION UNDER THE LOGIC OF ENTREPRENEURSHIP AND "SOCIAL IMPACT BUSINESS"}

\begin{abstract}
Universal Early Childhood Education is a recent achievement in Brazil, reached in 1988 with the new Federal Constitution. The National Education Plan (PNE) of 2014 defined as a goal a rate of enrollment of at least $50 \%$ of the children under three in daycare centers, reinforcing the obligation for children between four and five to be enrolled in pre-schools. However, according to INEP, in 2018, the actual enrollment levels were of $32.7 \%$ for the first age group and of $91.7 \%$ for the latter. It is in this scenario that the market has been finding a niche for "new products". In the present article we analyze the material named Entrepreneurship and social impact companies for early childhood, whose goal is "to support entrepreneurs interested in developing impact companies for early childhood." The analysis of this document indicates how poverty in early childhood has been transformed into merchandise, albeit under the pretext of a new form of philanthropy.
\end{abstract}

Keywords: Early Childhood, Entrepreneurship, Social Impact Business.

\footnotetext{
${ }^{1}$ Professora da Universidade de São Paulo. Faculdade de Filosofia, Ciências e Letras. Ribeirão Preto, São Paulo (SP), Brasil. biancacorrea@ffclrp.usp.br
} 


\section{EDUCACIÓN INFANTIL BAJO LA LÓGICA DEL EMPRENDIMIENTO Y EL “NEGOCIO DE IMPACTO SOCIAL"}

RESÚMEN: La educación infantil universal es un logro reciente en Brasil, alcanzado en 1988 con la nueva Constitución Federal. El PNE de 2014 estableció el objetivo de inscribir al menos el 50\% de los niños de hasta 3 años en guarderías, reforzando la obligatoriedad entre los 4 y 5 años. Sin embargo, según INEP, en 2018 la asistencia fue de $91,7 \%$ en preescolar y 32.7\% en el caso de las guarderías. Es en este escenario que el mercado ha encontrado un nicho más para ofrecer "nuevos productos". En este artículo analizamos el material titulado Emprendimiento y negocios de impacto social para la primera infancia, cuyo objetivo es "apoyar a los empresarios interesados en desarrollar negocios impactantes para la primera infancia". El análisis del documento indica cómo la pobreza en los primeros años de la infancia se ha convertido cada vez más en una mercancía, aunque bajo el pretexto de una nueva forma de filantropía.

Palabras clave: Educación Infantil como Derecho, La iniciativa empresarial, Negocio de Impacto Social.

\section{INTRODUÇÃO}

A educação infantil em creches e pré-escolas, de forma gratuita e disponível para todas as crianças desde o nascimento até os 5 anos e 11 meses, é conquista legal recente, tendo sido alcançada apenas em 1988 com a aprovação de uma nova Constituição Federal (CF/88). A partir da Emenda Constitucional 59 e da nova redação dada à Lei de Diretrizes e Bases da Educação Nacional (LDB) em 2013, a matrícula para crianças de 4 e 5 anos se tornou obrigatória. O Plano Nacional de Educação (PNE) aprovado em 2014 definiu como meta para uma década a matrícula de ao menos 50\% das crianças de até 3 anos em creches, reforçando-se a matrícula universal entre as de 4 e 5 anos.

Entretanto, os dados do censo escolar coletados pelo Instituto Nacional de Estudos e Pesquisas Educacionais Anísio Teixeira (INEP) em 2018 e divulgados em 2019 indicavam atendimento de $91,7 \%$ no caso da pré-escola e de apenas $32,7 \%$ no caso das creches. ${ }^{2}$ Assim, as metas do PNE e o atendimento à legislação em vigor não estão sendo cumpridos e, no contexto atual, enfrenta-se no Brasil uma crise econômica decorrente de políticas de austeridade com forte corte dos recursos para as políticas sociais.

É nesse cenário de falta de vagas contraposto a uma demanda cada vez mais crescente que o mercado tem encontrado nichos para a criação de "novos produtos". Neste artigo, analisamos o material intitulado Empreendedorismo e negócios de impacto social para a Primeira Infância organizado pela Fundação Maria Cecilia Souto Vidigal, cujo objetivo explícito é "apoiar empreendedores interessados em desenvolver negócios de impacto para a Primeira Infância."

Ao explicar qual seria o mercado, o material apresenta dados sobre a população infantil em situação de vulnerabilidade e, como possíveis produtos, cita, entre outros, "creches e pré-escolas de qualidade com baixo custo". Mencionam-se os negócios de impacto social (NIS) como potencial de minimização da desigualdade, afirmando-se que, assim, teríamos uma sociedade mais “próspera e sustentável”. Mas, neste artigo, perguntamos: próspera e sustentável para quem? Para as crianças pobres ou para o mercado? Essa é a questão que perseguimos ao longo da análise.

\footnotetext{
${ }^{2}$ Disponível em: <http://portal.inep.gov.br/artigo/-/asset_publisher/B4AQV9zFY7Bv/content/dados-do-censoescolarnumero-de- matriculas-na-educacao-infantil-cresceu-11-1-de-2014-a-2018/21206>. Acesso em: 15 jun. 2018. 


\section{PRIVATIZAÇÃO DA EDUCAÇÃO: MÚLTIPLAS FORMAS DE APROPRIAÇÃO DOS RECURSOS PÚBLICOS}

Conforme afirma Oliveira (2009), a história do desenvolvimento empresarial no campo da educação remonta à ditadura militar na década de 1960. Todavia, e de modo aparentemente paradoxal, é com a Constituição Cidadã de 1988 (CF/88) que a possibilidade de se obter lucro com a oferta educacional é explicitada, sendo reforçada posteriormente com a Lei de Diretrizes e Bases da Educação Nacional (LDB), em 1996. A partir daí, vimos crescerem os modelos e arranjos de negócios desenvolvidos por grandes escolas privadas, como a abertura de franquias, venda de materiais pedagógicos, entre outros. Num segundo momento, o setor privado começa a se apresentar a redes municipais e estaduais para a venda de pacotes pedagógicos que incluem material apostilado, formação de professores e programas para a gestão de escolas e redes de ensino (ADRIÃO; GARCIA; BORGHI, ARELARO, 2009; OLIVEIRA, 2009; GARCIA; ADRIÃO; ARELARO, 2012). Os autodenominados "sistemas privados de ensino" (SPE) começam a se propagar pelo País afora, atuando não apenas sobre o ensino fundamental, mas abarcando também a educação infantil, etapa que nos interessa discutir no presente artigo.

A história da educação infantil tem início nos anos de 1870 no Brasil, marcada por relações entre o público e o privado, uma vez que as primeiras vagas em creches são oferecidas por instituições filantrópicas (KUHLMANN JR, 1998). Mesmo quando o poder público passa a atuar, ele o faz por meio de convênios com instituições da sociedade civil, de forma complementar e não principal. Até a promulgação da Constituição Federal de 1988, ainda que o Estado tivesse ampliado sua participação com a oferta de vagas em creches e pré-escolas de modo direto, esse atendimento ainda era limitado, com um baixíssimo número de vagas para as crianças na faixa entre 0 e 6 anos de idade. Destaque-se que o atendimento em creche era vinculado à assistência social, e não às secretarias ou aos órgãos correlatos de educação. Com a aprovação da LDB de 1996, temos uma grande alteração na organização dessa etapa educacional, pois a lei estabeleceu prazo para que toda a oferta ficasse vinculada, nos municípios, aos órgãos responsáveis pela educação (secretarias, departamentos, diretorias etc.). Mesmo com essa alteração legal, o atendimento por meio de convênios se manteve como "alternativa", no art. 213 da CF/88, para atender à demanda por vagas, que foi aumentando à medida que a compreensão do direito foi se disseminando.

Em 2009, sob o pretexto de que as matrículas por convênio vinham crescendo sem a definição de critérios mínimos de qualidade, o próprio MEC, por meio da Coordenação da Educação Infantil (Coedi), lançou uma espécie de cartilha com orientações aos municípios quanto às condições para o estabelecimento de convênios com instituições sem fins lucrativos: comunitárias, confessionais ou filantrópicas (BRASIL, 2009a). Vale lembrar que o Fundeb, aprovado em 2006 e com vigência a partir de 2007, permitiu que recursos públicos desse fundo fossem destinados a instituições não lucrativas, o que se configurou como uma espécie de estímulo ao aumento das matrículas por conveniamento (BORGHI; BERTAGNA, 2016).

Para Correa e Adrião (2010, p. 12), com quem concordamos, "ao destinar cada vez mais recursos para essas instituições, mais o poder público se distancia da possibilidade de investir e ampliar sua rede própria." Considerando todos esses fatores, aliados a outras políticas educacionais de caráter neoliberal, Borghi et al. (2014) afirmam tratar-se de uma verdadeira "política nacional de conveniamento" que foi sendo construída nos últimos anos para ampliar o número de matrículas na educação infantil.

Assim, pode-se afirmar que no Brasil temos uma longa história de privatização da educação infantil, começando pelo atendimento filantrópico "tradicional", passando pelo conveniamento entre o poder público e instituições sem fins lucrativos, modelo que vem crescendo mesmo após a LDB e sendo incrementado a partir da aprovação do Fundeb, em 2006.

É preciso lembrar que a década de 1990 foi marcada por importantes reformas na política brasileira, de modo que "Essa reestruturação teve como paradigma a adoção dos critérios da economia privada na gestão da coisa pública" (OLIVEIRA, 2015, p. 629). Como decorrência, "as reformas dos anos 1990 contribuíram para o esmaecimento da noção de direito e da concepção de público que nos anos de 1980 orientou o processo constituinte brasileiro" (IDEM, p. 630).

Para Ball (2014, p. 34), “as fronteiras entre o Estado, a economia e a sociedade civil estão ficando turvas; há novas vozes nas conversas sobre as políticas e novos canais por meio dos quais os discursos sobre as políticas introduzem o pensamento sobre políticas (...)". Como decorrência do neoliberalismo, assistimos à emergência de "[...] novos tipos de atores sociais, sujeitos sociais híbridos 
que são espacialmente móveis, eticamente maleáveis e capazes de falar as linguagens do público, do valor privado e filantrópico" (BALL, 2014, p. 230). O mercado passa a ser visto como única alternativa para a solução dos problemas que o Estado, sob a ótica neoliberal, é incapaz de responder (BALL; OLMEDO, 2013).

Como se pode observar, toda essa movimentação tem resultado em múltiplas formas de privatização e, mais recentemente, temos assistido a novas estratégias de interação público-privada. Estamos falando, nesse caso, dos "contratos" ou "negócios" de "impacto social". Ao explicar os Contratos de Impacto Social (CIS), analisando o projeto pioneiro proposto para escolas de ensino médio público paulista, Cássio, Goulart e Ximenes argumentam, também, sobre seu caráter antiestatal (CÁSSIO; GOULART; XIMENES, 2018, p. 6-7).

$\mathrm{Na}$ próxima seção, apresentaremos o material que é nosso objeto de análise e que definimos, grosso modo, como um manual que estimula e orienta possíveis empreendedores dispostos a investir - direta ou indiretamente, captando recursos do Estado ou de parceiros privados - no atendimento à primeira infância. Tal manual pode ser visto como parte de um processo de constituição de redes (BALL, 2014), isto é, como constituinte daquele conjunto de ações que têm a ver com um novo olhar sobre o Estado, este passando da condição de "prestador" ou garantidor de direitos ao cidadão para a de "contratante" (Idem).

\section{EMPREENDEDORISMO E NEGÓCIOS DE IMPACTO SOCIAL: O QUE NOS INFORMA O MANUAL?}

Escrito por Sandra Mara Costa com a colaboração da Artemisia e da Danone Early Life Nutrition Brasil, o material intitulado "Empreendedorismo e Negócios de Impacto Social para Primeira Infância" foi publicado em 2016 no site da Fundação Maria Cecília Souto Vidigal "com o objetivo de apoiar empreendedores interessados em desenvolver negócios de impacto para a Primeira Infância” (FUNDAÇÃ̂ MARIA CECÍLIA SOUTO VIDIGAL, 2016, apresentação).

O material constitui-se numa espécie de "manual" e é composto por uma apresentação e cinco seções, a saber: Negócios de impacto social para a Primeira Infância; O que todo empreendedor de negócio de impacto para a Primeira Infância deve saber; Os desafios da Primeira Infância no Brasil; Oportunidades para negócios de impacto para a Primeira Infância e Referências para a avaliação de negócios de impacto social. Ao longo de 65 páginas, são apresentados os tópicos que, em tese, ensinariam aos interessados como empreender no campo da primeira infância.

Ainda na apresentação, e sem explicitar em que referências se baseia, ao afirmar que a ciência já comprovou que a forma como é vivida a primeira infância determinará toda a vida de uma pessoa, sustenta-se também que "o desenvolvimento saudável da criança (...) cria as bases de uma sociedade próspera, sustentável e com menos inequidade" (IDEM - grifos nossos).

Percebemos, já de início, que investir na infância não assegura a garantia de um direito cidadão desse sujeito de pequena idade, mas sim de um investimento para o futuro. Assim, desde o princípio parecem ficar claras as premissas do que será apresentado: trata-se de investimento numa sociedade vista como naturalmente desigual, ficando a incidência de atores privados responsável para que tal desigualdade seja minimizada. As causas da desigualdade não são sequer mencionadas, e nem o serão em nenhum ponto ao longo de todo o material. Apesar disso, sabe-se que no Brasil dos últimos anos temos enfrentado um aumento cada vez mais severo das desigualdades. Segundo matéria divulgada pela UOL em 20 de fevereiro de 2020, o Brasil é o sétimo país mais desigual do mundo (Forte, 2020).

Também na apresentação, afirma-se que os negócios de impacto social voltados para a primeira infância podem se constituir como um "possível agente de transformação social". Ao constatarmos as medidas propostas - que veremos mais adiante -, todas caracterizadas como sendo de

3 Disponível em: <https://www.fmcsv.org.br/pt-BR/biblioteca/empreendedorismo-e-negocios-de-impacto-social-parapi/>. Acesso em: 08 jul. 2020. 
baixo custo, podemos indagar: transformação para quem? Para as crianças pobres ou para os "empreendedores" que podem obter lucros com tais ações?

Na seção 1 do manual, na tentativa de se distinguir um negócio "tradicional" de um que gere impacto social, afirma-se que "Os negócios de impacto social propõem uma nova lógica, em que o principal objetivo é criar produtos e/ou serviços que solucionem problemas sociais, ao mesmo tempo que gerem lucro" (FUNDAÇÃO MARIA CECÍLIA SOUTO VIDIGAL, 2016, p. 8).

Observa-se, neste ponto, o que Ball (2014) discute como prática de uma construção discursiva que, ao defender o "empreendedorismo de políticas", promete a entrega de “desenvolvimento' e política de ajuda (por um lucro potencial)" (p. 38). Apesar das reais desigualdades sociais e econômicas do Brasil, as quais já mencionamos, é sempre bom lembrar, com o mesmo autor, que "Problemas de política são geralmente construídos ao invés de identificados" (IDEM, p. 41).

Portanto, embora a desigualdade de acesso a direitos básicos no Brasil seja uma realidade, as propostas em análise não vão à raiz do problema; ao contrário, procuram construir, nos termos de Ball (2014), quais seriam os "problemas" a serem enfrentados. Tais dificuldades, embora existam, são consequências de um sistema estruturalmente desigual e de escolhas políticas. Logo, medidas como a implementação de NIS são apenas paliativos que, mais uma vez, ajudam a escamotear o papel do Estado e as reais razões da desigualdade.

Chama a atenção a definição dada para o que seriam os negócios de impacto social e, principalmente, a definição do público-alvo: “(...) negócios de impacto social são empresas que oferecem, de forma intencional, soluções escaláveis para problemas sociais da população de baixa renda(...)" (IDEM, p. 8). Com tal escopo, os NIS teriam como peculiaridades alguns aspectos: "Foco na baixa renda (...); Intencionalidade (...); Potencial de escala (...); Rentabilidade; Impacto social relacionado à atividade principal (...); Distribuição ou não de dividendos (IBIDEM, p. 10 - grifos nossos). Pelo descrito, fica evidente como os termos utilizados estão muito mais no campo dos "negócios" do que no campo "social".

Apoiando-se na definição de pobreza de Amartya Sem, Prêmio Nobel de economia em 1998, afirma-se que "pobreza é a privação das capacidades básicas de um indivíduo, e não apenas o fato de possuir renda inferior a um patamar preestabelecido" (IBIDEM, p. 10, 2016). Essa ideia de pobreza vem se prestando a encobrir as desigualdades próprias do capitalismo que, com o avanço do neoliberalismo, só têm se aprofundado (BALL, 2014; DARDOT; LAVAL, 2016; LAVAL, 2019).

Trata-se de uma verdadeira falácia, pois não é possível imaginar que um indivíduo ou grupo de indivíduos possa viver bem, estando abaixo de um "patamar preestabelecido" de renda, apenas porque usufrui de certas "capacidades básicas". Quais seriam essas capacidades? Pelo discurso que vem ganhando força e sendo disseminado pelo Banco Mundial e por agendas globais em seus textos mais recentes, trata-se das habilidades socioemocionais, especialmente a resiliência (UNESCO, 2015). Logo, trata-se de desenvolver nos indivíduos que convivem com a pobreza e a desigualdade a capacidade de resistir às dores dessa condição sem se rebelar. Conforme matéria da Agência IBGE Notícias (NERY, 2019), mesmo considerando critérios do Banco Mundial, a pobreza e a extrema pobreza só vêm aumentando no País - no ano de 2018, eram 13,5 milhões com renda mensal per capita de $\mathrm{R} \$ 145$, ou seja, pessoas em condição de extrema pobreza. Além disso, pouco mais de 52 milhões de brasileiros viviam, naquele ano, com menos de R $\$ 420$ per capita por mês (NERY, 2019, s/p).

Com um discurso de convencimento, o manual passa a ideia de que empreender é tarefa para pessoas especiais e de que, no empreendedorismo social, os que assumem esse encargo seriam ainda mais especiais. Schumpeter, conhecido como o pai do empreendedorismo, em seu texto de 1945, afirma: "o empreendedor é alguém versátil, que possui habilidades para saber produzir, reunir recursos financeiros, organizar as operações internas e realizar as vendas da sua empresa" (FUNDAÇÃO MARIA CECÍLIA SOUTO VIDIGAL, 2016, p. 11).

Recorrendo-se a outro autor, Robert D. Hisrich, afirma-se que o empreendedorismo "é o processo de criar algo diferente e com valor" e, nesse sentido, a "satisfação econômica é resultado de um objetivo alcançado, um novo produto ou empresa, por exemplo, e não um fim em si mesmo.” Seguindo este raciocínio, afirma-se ainda que "A medida do sucesso passa pelo impacto social que sua iniciativa é capaz de gerar" (IBIDEM). 
Para Ball (2014), todavia, o empreendedorismo é um dos desdobramentos do próprio neoliberalismo. Assim, vê-se que o discurso é embasado em uma ideologia (IASI, 2017) que procura ocultar a realidade desigual existente, naturalizando-a e justificando sua eventual minimização por meio de ações como as do empreendedorismo social. Não há, no material, quaisquer evidências, ainda que sob a forma de relato de experiências, sobre a possibilidade real de que os NIS possam gerar "impacto social positivo". Como um negócio, está claro que o empreendedorismo social objetiva retorno financeiro; entretanto, procura-se dar uma ideia de benevolência às ações que levariam a tal retorno.

$\mathrm{Na}$ sequência do manual, o tópico "ecossistema de negócios" esclarece que ele deriva da biologia, numa analogia à vida interdependente, servindo para descrever "as comunidades de atividade econômica que se baseiam em plataformas de interação entre organizações e indivíduos cujas capacidades e papéis evoluem e se alinham ao longo do tempo" (IBIDEM, p. 12).

O manual também menciona os trabalhos da Força Tarefa de Finanças Sociais (FTFS), citando, nesse caso, o "Mapeamento dos Recursos Financeiros disponíveis no Campo Social do Brasil com o objetivo de identificar recursos potenciais para Finanças Sociais". Esse relatório é fruto de um levantamento visando identificar o potencial de investimentos existente, no qual se verificou um aporte de $\mathrm{R} \$ 13$ bilhões no Brasil, em 2014, por meio de "mecanismos de finanças sociais", estimando-se um potencial de R\$ 50 bilhões até 2020 (FUNDAÇÃO MARIA CECÍLIA SOUTO VIDIGAL, 2016, p. 13).

Infere-se, portanto, que não há melhor argumento do que este: o potencial de recursos disponíveis para incidir sobre a pobreza é a obtenção de lucro! E a pobreza no Brasil, que incide sobre a primeira infância, também é didaticamente apresentada em números. Assim, ao explicar qual seria o potencial de mercado, o material apresenta elementos sobre a população infantil em situação de vulnerabilidade, citando dados da Pesquisa Nacional por Amostra de Domićlios (Pnad) de 2014 e mencionando percentuais de crianças de 0 a 3 anos e as de 4 a 5 anos que estariam em situação de extrema pobreza. Este seria, pois, o público-alvo dos NIS (FUNDAÇÃO MARIA CECÍLIA SOUTO VIDIGAL, 2016).

Considerando que em 2019 já sentimos os efeitos da Emenda Constitucional 95 (BRASIL, 2016), a qual estabeleceu um teto de gastos por parte do governo e que afeta sobretudo as áreas sociais, com o crescimento nas taxas de desemprego e sob a vigência de um governo assumidamente favorável à privatização, é possível inferir que esse "mercado de pobres e muito pobres" tende a se ampliar - o que já aconteceu, como mostramos anteriormente, citando dados de 2018 da Agência IBGE Notícias.

Como já indicado, a questão da benevolência implícita nos NIS não passa por questionamentos quanto à pobreza e às desigualdades, mas se atém às possibilidades de lucro, quiçá produzindo "algum" impacto social. O documento define, por impacto social, o acesso a certos bens que possam trazer benefícios à primeira infância, benefícios estes que serão, no melhor dos casos, alcançados na vida adulta, quando esses sujeitos puderem melhor se adaptar à sociedade, ainda que persista a desigualdade econômica, que, por sua vez, é estrutural. Trata-se, portanto, de investimento em capital humano. Embora se mencionem no manual a legislação nacional e os deveres do Estado quanto aos direitos do cidadão desde seu nascimento, ele é enfático na produção discursiva segundo a qual o poder público, sozinho, não é capaz de responder a tais direitos. Nesse sentido, transforma direitos sociais em mercadorias, já que eles se tornam, como produtos a serem vendidos por empreendedores, elementos mensuráveis e rentáveis.

Prosseguindo nas explicações sobre as potencialidades do negócio, afirma-se que ele "abrange uma gama variada de atores" e, seguindo no discurso de convencimento que parece se dirigir a potenciais empreendedores, ainda temos a afirmação de que investimentos dessa natureza são cada vez mais vistos como "oportunidades relevantes" e atraem "investimentos de bancos, fundos de pensão, seguradoras, administradores de fortunas, fundações familiares e empresariais e investidores individuais" (IBIDEM, p. 13).

Encerrando a primeira seção do manual, uma lista de fontes de consulta é sugerida à página 15. Dentre elas, destacamos: Oportunidades de negócios de saúde para a população de baixa renda no Brasil e Oportunidades em educação para negócios focados na população de baixa renda no Brasil, ambas produções da Arthemisia, parceira na publicação do manual em análise. Apresentada como "uma organização sem fins 
lucrativos, pioneira na disseminação e no fomento de negócios de impacto social no Brasil", sua missão é "Identificar e potencializar uma nova geração de empreendedores(as) e negócios de impacto social que sejam referência na construção de um Brasil mais ético e justo." Apesar dessa descrição, a página da organização é aberta com a seguinte frase: "Entre ganhar dinheiro e mudar o mundo, fique com os dois."

Ora, se o capitalismo, em especial em sua fase de aprofundamento neoliberal, só sobrevive com a existência da desigualdade, para que alguns "ganhem dinheiro" é preciso que outros dele prescindam. Manter a desigualdade, pois, é uma necessidade para que os NIS possam continuar existindo. Há, portanto, na frase de abertura do site da organização, uma dupla contradição: em termos e fatos.

A seção 2 é dedicada a apresentar os principais conceitos sobre a primeira infância. Temas como o vínculo, o brincar e o uso de telas (tv, computadores, tablets etc.) são abordados. A ideia parece ser a de evidenciar como os NIS podem incidir nessa etapa da vida, oferecendo aos potenciais empreendedores conhecimentos básicos sobre a infância. Encerrando esta seção, a premissa sobre as razões para se investir na primeira infância é apresentada: trata-se de investir em capital humano para evitar custos futuros.

Citando o Núcleo Ciência Pela Infância (NCPI) - outra parceira constante da FMCSV que, ao que tudo indica, garante um verniz "científico" ao discurso construído e veiculado por ela -, advogase pela ideia de que prejuízos vividos na primeira infância decorrentes das desigualdades dificilmente serão "corrigidos" na vida adulta, gerando o que se denomina como ciclo intergeracional da pobreza (FUNDAÇÃO MARIA CECÍLIA SOUTO VIDIGAL, 2016, p. 28-29 - grifos nossos). Afirma-se exatamente o mesmo que encontramos em documento do Banco Mundial referente à Conferência sobre a Primeira Infância realizada em 2000 e publicado em 2010 no Brasil.

A apresentação do documento, assinada pela diretora executiva do BM à época, Mamphela Ramphele, embora contenha termos mais rudes, segundo nosso entendimento, argumenta com a mesma lógica do NCPI quanto ao "ciclo intergeracional da pobreza", afirmando que "a pobreza é como um gene ruim - é herdada (BANCO MUNDIAL, 2010, p. V - grifos nossos).

É assim que vamos identificando as relações entre o BM, as fundações ligadas a grandes bancos, como é o caso do Itaú, a própria Fundação Maria Cecília Souto Vidigal e outras organizações sociais, tais como a Artemisia, bem como a grupos que congregam pesquisadores de diferentes áreas e instituições científicas, como é o caso da NCPI. Temos assistido a um alinhamento que se dá em rede e que, ao fim e ao cabo, visa ao lucro, sem nenhum horizonte para eliminar as desigualdades, pois que estas são justamente o que alimenta as oportunidades de negócios sociais lucrativos.

$\mathrm{Na}$ seção 3 são apresentados dados sobre as "carências" identificadas na população infantil em termos de saúde e educação, principalmente. Este parece ser um item que prepara para o seguinte, no qual são expostos os assim chamados "campos em que a carência de produtos e serviços é maior para essa faixa etária” (FUNDAÇÃO MARIA CECÍLIA SOUTO VIDIGAL, 2016, p. 52).

Dessa forma, identifica-se onde há maior descumprimento da lei ou, em outras palavras, violação de direitos e, desse modo, considera-se o fato como "oportunidade" de negócios. Assim, embora o manual até mencione a legislação nacional que determina o direito à educação e à saúde desde o nascimento (no caso da saúde, o direito já é previsto às gestantes), não há qualquer problematização quanto ao fato de esses direitos não serem cumpridos.

$\mathrm{Na}$ seção 4, intitulada "Oportunidades para negócios de impacto para a Primeira Infância", são apresentados mais detalhadamente os campos abertos aos NIS, identificando-se grupos mais vulneráveis, tais como "gestantes, famílias e crianças de zero a seis anos, especialmente (...) da população de baixa renda" (FUNDAÇÃO MARIA CECÍLIA SOUTO VIDIGAL, 2016, p. 52 grifos nossos). O documento, mais uma vez, deixa evidente, por meio da linguagem utilizada, tratar-se de negócios, muito mais do que de filantropia, ao afirmar, na sequência, que: "Conforme as características de cada localidade, certamente algumas delas têm mais potencial de mercado e escala do que outras" (IDEM, p. 53).

A expressão "baixo custo" é mencionada nove vezes ao longo do texto. Contudo, ao introduzir os campos passíveis de investimento, apela-se para expressões menos carregadas

\footnotetext{
${ }^{4}$ Disponível em <https://artemisia.org.br/quemsomos/>. Acesso em: 13/05/2020. Educação em Revista|Belo Horizonte|v.36|e231100|2020
} 
negativamente: "Nossa aposta é que você, com tudo o que leu e aprendeu até aqui, esteja com o tino mais apurado para identificar as soluções de negócios mais interessantes para investir: aquelas que atendam necessidades reais, apresentem custo acessível e qualidade honesta e que gerem impacto social" (IBIDEM - grifos nossos). Neste ponto, diferentemente do que se insiste em muitas outras passagens, fala-se em "qualidade honesta", e não em "qualidade". A pergunta que resta é: honesta para quem?

Quanto aos produtos e serviços possíveis de se tornarem negócios, transcrevemos alguns exemplos para os diferentes campos a fim de evidenciar até onde tem chegado esse tipo de visão que transforma direitos em mercadorias de modo tão explícito (IDEM, p. 53-57): Pré-natal, parto e nascimento; Parentalidade; Saúde da criança, Educação e Brincadeiras e interações com a natureza. No caso da educação infantil, as possibilidades de negócios são detalhadas da seguinte maneira:

* Creches e pré-escolas de qualidade com baixo custo.

* Produção de mobiliário adequado e de baixo custo para berçários, creches e pré-escolas.

* Qualificação de profissionais da educação infantil - módulos presenciais e a distância.

* Desenvolvimento de projeto arquitetônico para creches e pré-escolas públicas e/ou conveniadas, atentando para as características de cada região.

* Soluções para espaços lúdicos, com qualidade e baixo custo, para creches e pré-escolas.

* Aplicativos ou ferramentas voltadas à gestão de creches e pré-escolas (FUNDAÇÃO MARIA CECÍLIA SOUTO VIDIGAL, 2016, p. 56).

Em relação à educação, como descrito acima, os exemplos reforçam que a área de incidência para os NIS é composta por ações que, segundo nossa legislação, deveriam estar sob a responsabilidade do Estado, admitindo-se o estabelecimento de convênio entre este e instituições sem fins lucrativos. Estamos, portanto, falando de vagas em creches e pré-escolas; em mobiliário que deveria ser parte das condições de oferta seguindo padrões de qualidade; em formação continuada de professores - o manual menciona "qualificação" -; entre outros.

Assim, se temos uma história de filantropia ou terceirização da educação infantil, como já citado no início deste trabalho, hoje vemos avançar esse modelo, mas com uma importante "novidade": o expresso objetivo de se obter lucro. Em outras palavras, poder-se-ia dizer que a novidade aqui diz respeito ao que Ball (2014) define como nova filantropização ou edu-business.

A manutenção dos convênios com entidades sem fins lucrativos, após a implementação dos dois principais fundos de financiamento da educação brasileira (Fundef e Fundeb ${ }^{5}$ ), para o atendimento em creches, tem impactado negativamente a oferta de vagas em instituições públicas. Ademais, estudos na área têm evidenciado que a qualidade das instituições conveniadas é invariavelmente inferior àquela oferecida em instituições públicas (CAMPOS; CRUZ, 2006; CAMPOS; FULLGRAF; WIGGERS, 2006; SUSIN, 2008; FRANCO; DOMICIANO; ADRIÃO, 2019). A experiência brasileira, portanto, mostra que, mesmo havendo normas a seguir quando a instituição não é pública, a falta de fiscalização prevalece e, com ela, um atendimento de baixíssima qualidade é oferecido a nossas crianças, no caso, às mais pobres, as mesmas que agora passam a ser alvo dos NIS.

Se, sem visar ao lucro, assistimos a situações vexatórias no atendimento conveniado - como bem discutido em pesquisa de Maria Aparecida Ciavatta Franco (1984) já na década de 1980, e em outras mais recentes, como as de Amabile Silva Paschoim (2008), na qual, entre outros problemas, a autora constata que a creche conveniada estudada cobrava mensalidade das famílias sem que o poder público com quem era estabelecido o convênio soubesse -, o que se pode esperar quando se assume explicitamente como proposta um atendimento de "baixo custo" que visa retorno financeiro?

\footnotetext{
${ }^{5}$ Fundef: Lei n. 9.424, de 24 de dezembro de 1996. Dispõe sobre o Fundo de Manutenção e Desenvolvimento do Ensino Fundamental e de Valorização do Magistério - Fundef. Diário Oficial da União, Brasília, DF, 26 dez. 1996.

Fundeb: Lei $\mathbf{n}^{\mathbf{0}}$ 11.494, de 20 de junho de 2007. Regulamenta o Fundo de Manutenção e Desenvolvimento da Educação Básica e de Valorização dos Profissionais da Educação - Fundeb, de que trata o art. 60 do Ato das Disposições Constitucionais Transitórias; altera a Lei no 10.195, de 14 de fevereiro de 2001; revoga dispositivos das Leis nos 9.424, de 24 de dezembro de 1996, 10.880, de 9 de junho de 2004, e 10.845, de 5 de março de 2004; e dá outras providências. Brasília, DF, 21 jun. de 2007.
} 
A última seção do manual é toda dedicada a esclarecer sobre a imprescindibilidade da avaliação como condição para o sucesso dos NIS. Assim, temos a afirmação de que "negócios de impacto social são empreendimentos que têm a missão explícita de gerar impacto socioambiental, ao mesmo tempo que geram resultado financeiro positivo e de forma sustentável" (FUNDAÇÃO MARIA CECÍLIA SOUTO VIDIGAL, 2016, p. 58). Nesse sentido, argumenta-se sobre a importância da avaliação que menciona o artigo assinado pelo Instituto de Cidadania Empresarial (ICE), e a Move que estabelece o campo dos negócios sociais como "emergente" e "dependente" de demonstrar seus diferenciais, daí a relevância de boas formas de avaliação (IBIDEM, p. 59).

Novamente, fica explícita a ação em rede empreendida por parceiros do setor privado: ICE, Move e a própria FMCSV, além da Fundação Itaú Social, várias vezes mencionada como referência ao longo do texto. No caso da avaliação, o documento destaca o papel da Fundação Itaú Social como principal difusora de uma "cultura da avaliação", que tem oferecido "cursos, seminários e materiais de apoio na área e difundido um conceito bastante didático sobre o tema" (FUNDAÇÃO MARIA CECÍLIA SOUTO VIDIGAL, 2016, p. 59).

De fato, ao entrarmos no site da Fundação Itaú, encontramos um extenso número de cursos, presenciais ou na modalidade $\mathrm{EaD}$, bem como documentos para consulta sobre procedimentos para avaliação de NIS. Como já mencionado a partir de Ball e Olmedo (2013), a rede de empresários e banqueiros por meio de seus institutos e fundações cumpre um importante papel no "ecossistema de negócios".

Ao estabelecer as "Dimensões da avaliação", no fim do manual, são descritas as seguintes: "Avaliação de processo; Avaliação de resultados; Avaliação de impacto e Avaliação econômica." Sobre esta última dimensão, ao descrevê-la, o texto é claro ao se referir à necessária lucratividade que o negócio deve garantir, pois ela: "Mede o impacto e a taxa de retorno de um conjunto de ações; analisa o custobenefício, comparando os recursos usados em um programa e seus resultados" (IBIDEM, p. 61 - grifos nossos).

Finalmente, fica evidente que a própria avaliação do negócio, objeto de uma longa argumentação no manual, é também um campo de "negócio de impacto social"; ou seja, ao empreender, já se devem vislumbrar os custos da avaliação, sendo o investidor no negócio um "forte candidato para financiar a avaliação, que deve ser prevista o quanto antes" (IBIDEM, p. 63). Logo, os empreendedores sociais devem prever em suas propostas iniciais os custos para a sua avaliação e, se os recursos vierem dos cofres públicos, devem demandar ainda mais dinheiro do "investidor" ou "contratante" (Ball, 2014), que, no caso, pode ser o poder público.

\section{CONSIDERAÇÕES FINAIS}

Embora o manual alegue se respaldar em conhecimento científico, ele menciona, em suma, apenas alguns economistas, reforçando os argumentos de que investir na primeira infância pode gerar ganhos a médio e longo prazos. Ademais, não há elementos que atestem a melhor qualidade do atendimento por meio dos NIS em comparação com o que temos de oferta pública no caso da educação infantil. Se é verdade que ainda não temos vagas em creches públicas para todas as crianças, não é menos verdadeiro afirmar que, dada a sua superioridade em termos de qualidade, o que se deve fazer é buscar sua ampliação. Uma pesquisa desenvolvida na Inglaterra (TAGGART et al, 2011), país bastante distinto do nosso em uma série de aspectos, evidencia que, também naquele contexto, as escolas de educação infantil públicas e mantidas exclusivamente pelo poder público apresentam qualidade superior às demais (privadas com ou sem fins lucrativos).

Para além do negócio em si, é preciso destacar como se têm multiplicado as ações e a disseminação de uma ideologia que coloca o mercado cada vez mais como o único capaz de resolver todo e qualquer tipo de desafio social, sem nenhum questionamento sobre as origens da desigualdade. $\mathrm{O}$ modelo das charter, que seriam formas de terceirização ou conveniamento, tem sido frequentemente anunciado como a saída para os problemas da educação, especialmente no ensino fundamental e no médio (ADRIÃO; DOMICIANO, 2018). Entendemos haver entre essa defesa do modelo charter e os NIS uma relação direta de interesses. 
No Brasil, o acesso à educação infantil como direito dos filhos de trabalhadores urbanos e rurais, e das próprias crianças de 0 aos 5 anos e 11 meses, é fruto de muita luta e só foi reconhecido em 1988, como já mencionado. Passados mais de trinta anos da CF/88, hoje assistimos a diversas tentativas de destruição desse ideário segundo o qual a educação é direito, e não mercadoria. Nas palavras de Moss (2009, p. 419), as "instituições de educação infantil são facilmente vistas como lugares para governar crianças por meio da aplicação de tecnologias humanas cada vez mais poderosas, e como provedoras de mercadorias a serem negociadas no mercado de cuidado de crianças."

Assim, se temos em nossa história uma vasta experiência em "lidar pobremente com a pobreza" (FRANCO, 1984), se temos, também, uma longa história marcada por orientações externas que nos sugerem "alternativas" a baixo custo na educação infantil (ROSEMBERG 2001; 2002; 2003), a atualidade coloca-nos diante de novos desafios para defender que todas as crianças são sujeitos de direitos e, como tais, não podem agora se tornar meros objetos com potencial de gerar lucros: não podem se tornar meras mercadorias, ou, exagerando numa analogia, commodities.

A educação infantil precisaria ser vista como direito de todos em oposição ao privilégio de alguns, sejam esses parte da população mais abastada, sejam esses parte da população mais empobrecida que alcança ou é alcançada por negócios de impacto social. Não bastasse viver na pobreza, as crianças podem perder seu status de cidadãs desde o nascimento, transformando-se em objetos que podem gerar dividendos diretamente a esta ou aquela organização social que explicitamente visa o lucro.

A educação infantil, como parte da educação básica no Brasil pós-Constituição Federal de 1988 e LDB de 1990, precisa voltar a ser entendida conforme nos explicava Cury, já em 2008: “Como direito, ela significa um recorte universalista próprio de uma cidadania ampliada e ansiosa por encontros e reencontros com uma democracia civil, social, política e cultural” (CURY, 2008, p. 294).

Entender como essa dinâmica vem se construindo sob o manto da benevolência destinada à primeira infância, ou, em outros termos, o filantrocapitalismo (OLMEDO; BALL, 2016), é condição sine qua non para defendermos a criança cidadã e sujeito de direitos desde o nascimento, tal como determinado em nossa CF/88 e reafirmado pelo Estatuto da Criança e do Adolescente (BRASIL, 1990).

Concluímos, por ora, que os negócios de impacto social só podem tornar mais "próspera e sustentável" a vida daqueles que estão por trás das grandes corporações e, quiçá, dos médios empreendedores de NIS que se arriscam no negócio de obter lucro sobre a vida de crianças pobres. Para estas, a superação da desigualdade não parece estar no horizonte dessa forma de tratamento, que lhes nega o direito em sua perspectiva universalista.

\section{REFERÊNCIAS}

ADRIÃO, T. DOMICIANO, C. A. A Educação Pública e as Corporações: avanços e contradições em uma década de ampliação de investimento no Brasil. FINEDUCA - Revista de Financiamento da Educação, Porto Alegre, v. 8, n. 3, 2018. p. 1-18

ADRIÃO, T.; GARCIA, T.; BORGHI, R. F.; ARELARO, L. R. G. Uma modalidade peculiar de privatização da educação pública: a aquisição de 'sistemas de ensino' por municípios paulistas. Educação \& Sociedade (Impresso), v. 30, p. 799-818, 2009.

BALL, S. J.; OLMEDO, A. A 'nova' filantropia, o capitalismo social e as redes de políticas globais em educação. In: Redefinições das fronteiras entre o público e o privado: implicações para a democratização da educação. Organizadora: Vera Maria Vidal Peroni. Brasília: Liber Livro, 2013. 352 p.

BALL, Stephen J. Educação Global S. A.: novas redes de políticas e o imaginário neoliberal. Tradução de Janete Bridon. Ponta Grossa: UEPG, 2014. 270 p. 
BANCO MUNDIAL. Do desenvolvimento da primeira infância ao desenvolvimento humano: investindo no futuro de nossas crianças / Mary Eming Young, (organizadora); tradução Magda Lopes. São Paulo: Fundação Maria Cecilia Souto Vidigal, 2010.

BORGHI, R. F.; BERTAGNA, R. H, Que educação é pública? Análise preliminar do atendimento conveniado na educação infantil nas diferentes regiões administrativas brasileiras. Rev. bras. Estud. pedagog. (on-line), Brasília, v. 97, n. 247, p. 506-518, set./dez. 2016.

BORGHI, R.; BERTAGNA, R. H.; ADRIÃO, T.; CORREA, B. C.; GARCIA, T. O. G. Subsídios públicos para instituições privadas de educação infantil: análise de tendências em municípios paulistas. In: VIEIRA, M. V.; MEDINA, S. (Org.). Trabalho docente e políticas educacionais para a educação: desafios contemporâneos. Uberlândia: Ed. da UFU, 2014. p. 131-150.

BRASIL. Congresso Nacional. Constituição da República Federativa do Brasil. Brasília: Senado Federal/Centro Gráfico, 1988.

BRASIL. ECA: Estatuto da criança e do adolescente. Lei federal nº 8.069 de 13/07/90.

BRASIL. Emenda Constitucional n. 59, de 11 de novembro de 2009. Diário Oficial da União. Brasília, DF, 2009.

BRASIL. LDB: Lei de Diretrizes e bases da Educação Nacional. Lei no 9.394 de 20/12/96.

BRASIL. Lei $\mathbf{n}^{\mathbf{0}} \mathbf{1 2 . 7 9 6}$, de 4 de abril de 2013. Altera a Lei no 9.394, de 20 de dezembro de 1996, que estabelece as diretrizes e bases da educação nacional, para dispor sobre a formação dos profissionais da educação e dar outras providências.

BRASIL. Lei nº 13.005, de 25 de junho de 2014. Plano Nacional de Educação (2014-2024).

BRASIL. Orientações sobre convênios entre secretarias municipais de educação e instituições comunitárias, confessionais ou filantrópicas sem fins lucrativos para a oferta de educação infantil. Brasília: MEC, SEB, 2009. 96 p.

BRASIL. Emenda Constitucional n. 95, de 2016. Brasília, em 15 de dezembro de 2016. Altera o Ato das Disposições Constitucionais Transitórias, para instituir o Novo Regime Fiscal, e dá outras providências.

BRASIL. Instituto Nacional de Estudos e Pesquisas Educacionais Anísio Teixeira. Relatório do $2^{\circ}$ Ciclo de Monitoramento das Metas do Plano Nacional de Educação - 2018. Brasília, DF : Inep, 2018.

CAMPOS, M. M.; CRUZ, S. H. V. Consulta sobre qualidade na educação infantil: o que pensam e querem os sujeitos deste direito. São Paulo: Cortez, 2006.

CAMPOS, M. M.; FULLGRAF, J.; WIGGERS, V. A qualidade da Educação Infantil brasileira: alguns resultados de pesquisa. Cadernos de Pesquisa. São Paulo, n. 127, p. 87-128, 2006.

CÁSSIO, F. L.; GOULART, D. C.; XIMENES, S. B. Contratos de Impacto Social na Rede Estadual de São Paulo: Nova Modalidade de Parceria Público-Privada no Brasil. Arquivos Analíticos de Políticas Educativas. Vol. 26, n. 130, p. 2-25, 2018. 
CORREA, B. C.; ADRIÃO, T. A educação de crianças de zero a seis anos: contradições na garantia de um direito. Revista ADUSP, São Paulo, v. 48, p. 6-13, 2010.

CURY, C. R. J. A EDUCAÇÃO BÁSICA COMO DIREITO. Cadernos de Pesquisa, v. 38, n. 134, maio/ago. p. 293-303, 2008.

DARDOT, P.; LAVAL, C. A nova razão do mundo: ensaio sobre a sociedade neoliberal. Tradução de Mariana Echalar. 1ª ed. São Paulo: Boitempo, 2016.

FORTE, B.. Por que o Brasil é o sétimo país mais desigual do mundo. Disponível em: https://www.uol.com.br/ecoa/ultimas-noticias/2020/02/20/por-que-brasil-e-o-setimo-pais-maisdesigual-do-mundo.htm. Acesso em: 25 mar. 2020.

FRANCO, D. S.; DOMICIANO, C. A.; ADRIÃO, T. Privatização das creches em São Paulo e seus efeitos sobre a qualidade da oferta. Teoria e Prática da Educação, v. 22, p. 80-96, 2019.

FRANCO, M. A. C. Lidando pobremente com a pobreza. Análise de uma tendência no atendimento a crianças "carentes" de 0 a 6 anos de idade. Cad. Pesq., São Paulo (51): 13-32, nov. 1984.

FUNDAÇÃO MARIA CECÍLIA SOUTO VIDIGAL (org). Empreendedorismo e negócios de impacto social para a Primeira Infância. 1a ed., São Paulo: Fundação Maria Cecília Souto Vidigal, 2016. Disponível em: https://issuu.com/fmcsv/docs/empreendedorismo_e_nis_para_pi_vers. Acesso em: 21 out. 2019.

GARCIA, T. G.; ADRIÃO, T.; ARELARO, L. R. G. O Programa Gestão Nota 10 do Instituto Ayrton Sena na Rede municipal de ensino de São José do Rio Preto: consequências para a gestão educacional. Revista FAED UNEMAT, v. 18, p. 123-142, 2012.

IASI, Mauro. Política, Estado e ideologia na trama conjuntural. São Paulo: Instituto Caio Prado Jr., 2017, 144 páginas.

INEP. Notas Estatísticas Brasília-DF | Fevereiro de 2018. Disponível em: http://portal.mec.gov.br/docman/fevereiro-2017-pdf/59931-app-censo-escolar-da-educacao-basica2016-pdf-1/file. Acesso em: 15 jun. 2018.

KUHLMANN Jr., Moysés. Infância e Educação Infantil: uma abordagem histórica. Porto Alegre, RS: Mediação, 1998.

LAVAL, C. A escola não é uma empresa: o neoliberalismo em ataque ao ensino público. Trad. Mariana Echalar. 1. Ed. São Paulo: Boitempo, 2019.

MOSS, P. Introduzindo a política na creche: educação infantil como prática democrática. Psicologia USP, São Paulo, jul/set, 2009, p. 417-436.

NERY, C. Extrema pobreza atinge 13,5 milhões de pessoas e chega ao maior nível em 7 anos. Agência IBGE Notícias. 2019. Disponível em: https://agenciadenoticias.ibge.gov.br/agencia-noticias/2012-agenciade-noticias/noticias/25882-extrema-pobreza-atinge-13-5-milhoes-de-pessoas-e-chega-ao-maior-nivelem-7-anos Acesso em 30/11/2019. Acesso em: 18 out. 2019.

OLIVEIRA, D. Nova gestão pública e governos democrático-populares: contradições etre a busca da eficiência e a ampliação do direito à educação. Educ. Soc., Campinas, v. 36, nº 132, p. 625-646, jul.set., 2015. 
OLIVEIRA, R. P. A transformação da educação em mercadoria no Brasil. Educ. Soc., Campinas, vol. 30, n. 108, p. 739-760, out. 2009.

OLMEDO, A.; BALL S. Filantrocapitalismo: la tirania del dar. 2016. Disponível em: https://www.unite4education.org/es/privatizacion-educativa-2/filantrocapitalismo-la-tirania-de-dar/ Acesso em: 20 abr. 2016.

PASCHOIM, A. S. Práticas pedagógicas na educação infantil: o cuidar e o educar em questão. Monografia de conclusão de curso. Faculdade de Filosofia, Ciências e Letras de Ribeirão Preto. Ribeirão Preto, 2008. 89 p.

ROSEMBERG, F. Avaliação de programas, indicadores e projetos em educação infantil. Revista Brasileira de Educação, n. 16, p. 19-26, jan/fev/mar/abr. 2001.

ROSEMBERG, F. Organizações multilaterais, estado e políticas de educação infantil. Cadernos de Pesquisa, n. 115, p. 25-63, mar. 2002.

ROSEMBERG, F. Sísifo e a educação infantil brasileira. Pro-Posições, vol. 14, n. 1 (40), p. 177-198, jan/abr. 2003.

SUSIN, M. O. O estatal e o público não estatal: onde está a educação infantil comunitária em Porto Alegre? In: PERONI, v. m. v.; ADRIÃO, T. (orgs.). Público e Privado na Educação: novos elementos para o debate. 1. ed. São Paulo: Xamã, 2008. p. 67-78.

TAGGART, Brenda; SYLVA, Kathy; MELHUISH, Edward; SAMMONS, Pam; SIRAJBLATCHFORD, Iram. (Tradução Eliana Bhering). O poder da pré-escola: evidências de um estudo longitudinal na Inglaterra. Cadernos de Pesquisa. v.41, n.142 jan./abr. p. 68-99, 2011.

UNESCO. EDUCAÇÃO 2030. Declaração de Incheon - Rumo a uma educação de qualidade inclusiva e equitativa e à educação ao longo da vida para todos. Incheon, Coreia do Sul, 2015. Disponível em: http://unesdoc.unesco.org/images/0024/002432/243278POR.pdf. Acesso em: 20 maio 2020.

Submetido: $15 / 11 / 2019$

Aprovado: $10 / 07 / 2020$ 